\title{
Reflexões sobre o envelhecimento: contribuições da universidade aberta como estratégia de promoção da saúde
}

\author{
Reflections on aging: contributions open university as a strategy \\ Health promotion
}

\author{
Yadira Arnet Fernandez* \\ Nanci Soares** \\ Regina Celia de Souza Baretta*** \\ Thercius Oliveira Tasso****
}

\section{Resumo}

O cenário mundial passa por grandes transformações demográficas, consideradas um fenômeno, sem precedentes. A longevidade é um dos maiores triunfos da humanidade, com implicações profundas para as políticas públicas, para os sistemas de saúde, orçamentos, com urgente necessidade, que requer ações imediatas, capacitações profissionais e abordagem multidimensional. Neste ensaio teórico pretende-se abordar reflexões sobre o envelhecimento e as contribuições da Universidade Aberta à Terceira Idade (UNATI), como estratégia de promoção em saúde. Muitos estudos se dedicam às questões ligadas ao bem-estar, que viabilizem a longevidade, com qualidade de vida. As UNATIS, podem evidenciar ações de promoção da saúde, no envelhecimento humano, interferindo na autoestima e nos cuidados básicos de saúde, corroborando no desenvolvimento de competências e recursos, para o enfrentamento de vulnerabilidades individuais e ambientais. A educação em saúde influencia sentimentos de libertação e mudanças sociais, tornando-se uma estratégia de empoderamento dos sujeitos. O envelhecimento saudável fomenta a qualidade de vida, a partir da interdisciplinaridade, da participação das pessoas idosas em grupos, do controle de condições e estilos de vida, mais saudáveis. É preciso ampliar o olhar acerca do envelhecimento, para que os idosos, sejam protagonistas de direitos e deveres, com manutenção de autonomia, autoconfiança.

Palavras chaves: Envelhecimento; Desafios, Universidade aberta, Promoção de Saúde, Empoderamento.

\section{Abstract}

The world scenario is undergoing major demographic changes, considered an unprecedented phenomenon. Longevity is one of humanity's greatest triumphs, with profound implications for public policies, for health systems, budgets, with an urgent need, which requires immediate action, professional training and a multidimensional approach. This theoretical essay aims to address reflections on aging and the contributions of the Open University to the Elderly (UNATI), as a health promotion strategy. Many studies are dedicated to issues related to well-being, which enable longevity, with quality of life. UNATIS can demonstrate health promotion actions in human aging, interfering in self-esteem and basic health care, corroborating the development of skills and resources, to face individual and environmental vulnerabilities. Health education influences feelings of liberation and social changes, becoming a subject empowerment strategy. Healthy aging promotes quality of life, based on interdisciplinarity, the participation of older people in groups, the control of healthier conditions and lifestyles. It is necessary to broaden the view on aging, so that the elderly are protagonists of rights and duties, with maintenance of autonomy, self-confidence.

\footnotetext{
* Doutorando do Programa de Pós-graduação em Promoção de Saúde da UNIFRAN.

** Assistente Social e docente do programa de pós-graduação em Serviço Social da UNESP campus de Franca, coordenadora da UNATI.

*** Assistente Social, docente e pesquisadora do Programa de Pós-graduação em Promoção de Saúde da UNIFRAN.

**** Doutor em ciencia pela UNIFRAN. Pós doutorando do programa de pos graduação em promoção da saude.
} 
Key words: Aging; Challenges, Open University, Health Promotion, Empowerment. 
Introdução

O mundo está passando por uma transformação demográfica, considerada um fenômeno sem precedentes na história (KALACHE, 2012). Os avanços na medicina e na tecnologia biomédica, quando combinado com as quedas acentuadas nas taxas de fertilidade, natalidade, mortalidade infantil, tem alertado a todos, sobre o aumento considerável na expectativa de vida da população idosa, onde a longevidade não é mais um assunto para o futuro (VENTURA, 2012).

Apesar de se considerar a longevidade como um dos maiores triunfos da humanidade (WHO, 2005), a velocidade com que mais e mais pessoas superam as barreiras cronológicas estabelecidas como estágio da velhice, demanda uma resposta abrangente, e urgente, por parte do sistema de saúde pública, tendo em conta que, as consequências dessas mudanças são impressionantes e as implicações são profundas, para as políticas públicas, para os sistemas de saúde, para os orçamentos e uma necessidade de capacitação de profissionais de diversas áreas. Nesse sentido, a Organização Mundial da Saúde (OMS) expressa à importância e a urgência de mudanças profundas, na maneira de formular políticas e prestar serviços às pessoas que envelhecem (WHO, 2015).

Prata et al (2011) afirmam que as demandas advindas desse processo, geram uma nova realidade, uma vez que, em um contexto em que persistem outros problemas sociais, como a pobreza e a exclusão social, não basta apenas viver mais tempo, é preciso viver com qualidade. O desafio se coloca de forma peculiar, a cada ano conquistado é preciso prover melhores condições de enfrentar o envelhecimento e a velhice de forma autônoma e independente. Contudo, o debate tem sido insuficiente e as evidências, do que pode ser feito é ainda limitada, baseada nas medidas de minimização e combate à exclusão e de igualdade de oportunidades sociais, para a pessoa idosa. Nesse sentido Costa; Costa; Gobbi (2012), alertam que, a sociedade ainda está despreparada diante do grande aumento da população idosa, o que nos obriga a repensar conceitos ainda arraigados, estereótipos ultrapassados e estigmas relacionados a esse segmento.

Como consequência de uma população mais envelhecida, ações chaves relacionadas com a promoção e a educação em saúde, precisam ser ampliadas para permitir a manutenção da independência e da autonomia (VERAS; CALDAS, 2013). Desta forma, a promoção da saúde 
tem um papel fundamental no desenvolvimento de competências e recursos, para o enfrentamento de vulnerabilidades individuais e ambientais. Nesse sentido, estudos sobre o processo de envelhecimento tem recebido especial atenção, no que diz respeito às questões ligadas ao bem-estar e a políticas, que viabilizem não só que as pessoas vivam mais anos, mas que esses sejam de qualidade de vida (LE PHAM; VO, 2015). Assim, qualquer política direcionada ao idoso, deve levar em conta a promoção da saúde, visando otimizar a saúde física e cognitiva e a produtividade ao longo da vida (VERAS, 2012aㅡ).

Por tanto, iniciativas de inserção social promovidas pelos diferentes atores sociais, devem ter uma abordagem integrada das diversas políticas setoriais, como saúde, assistência social, previdência, educação, esporte e lazer, que exerçam um papel crucial no âmbito da coesão social, e seja diretamente proporcional a melhoria das condições de saúde, oferta de emprego, acesso à educação, redução da criminalidade, entre outros, que propiciaria uma melhoria da qualidade de vida da população em geral (WIXEY, et al. 2005, p. 18).

Nessa linha de raciocínio, as estratégias de promoção do envelhecimento saudável, ancoradas na educação em saúde, é uma alternativa eficaz para promover conhecimentos, fomentando a qualidade de vida, a partir de pressupostos de interdisciplinaridade, participação social e promoção da saúde. A melhoria e ampliação de políticas públicas, o estimulo à participação das pessoas idosas em grupos, controle de condições de vida de idosos (alimentação, educação continuada, esportes, lazer, hábitos e atitudes), pode transformar a realidade social, empoderando o idoso, para que reivindique ações que melhorem sua condição de vida e de saúde.

Neste ensaio teórico pretende-se abordar reflexões sobre o envelhecimento e as contribuições da universidade aberta à terceira idade (UNATI), como estratégia de promoção em saúde, por meio do desenvolvimento de oficinas de educação em saúde

\section{Dilemas e desafios de envelhecer em Brasil no século XXI}

A realidade do envelhecimento populacional brasileiro, é derivada das alterações na transição epidemiológica, que são claras, inequívocas e irreversíveis. Com tudo, nos últimos anos, apesar de ter ocorrido muitas discussões sobre o processo de envelhecimento, ainda 
prevalecem às mudanças intrínsecas, pois há certa falta de clareza para a sociedade e para suas instituições (FERNANDES; SOARES, 2012).

Nesse sentido poder-se-ia dizer que o envelhecimento demográfico tornou-se um desafio ético, o qual exige de um olhar interdisciplinar e qualificado para cuidar dessa população crescente de idosos, já que é nessa fase onde as mudanças advindas do envelhecimento cronológico, desencadeiam uma elevada prevalencia de doenças crônicas e incapacitantes que atigem fundamentalmente as camadas mais pobres da população e grupos mais vulneráveis, como os idosos e a população de baixa escolaridade e renda (MALTA; MORAIS NETO; SILVA JUNIOR, 2011).

Simultaneamente as rápidas mudanças demográficas, outras profundas transformações tanto culturais, quanto sociais, ocorrem na sociedade, motivo pelo qual, nos faz refletir sobre a capacidade de sustentabilidade da economia do Brasil, para enfrentar esse fenômeno e os desafios para o Estado, na conquista social de maior longevidade. Sendo assim, exige-se uma maior compreensão sobre os idosos, a fim de serem entendidos como cidadãos detentores de direitos e não apenas pessoas vulneráveis, que necessitam receber assistência e cuidados (MONTEAGUDO; GARCÍA, 2018).

Reconhecendo que, a conquista da longevidade não é sinônimo de qualidade de vida, os autores Campelo e Paiva (2014, p. 27), enfatizam que a longevidade não é um privilégio de todas as nações: A desigualdade social existente até os dias de hoje, "marca substancialmente a vida de milhões e milhões de indivíduos de todas as idades, protagonizando uma situação quase irreversível, de não realização das suas necessidades". Os autores exemplificam como a qualidade de vida resulta de investimentos como no Japão e a África. De acordo com o Relatório da Organização Mundial da Saúde (2005), uma criança nascida no Japão, em 2003, espera viver, em média, 85 anos, contanto com pelo menos US\$550 gastos na sua saúde (por ano); uma criança em Serra Leoa (África ocidental), provavelmente não viveria além de 36 anos, no país onde apenas US\$ 3,00, seriam gastos com sua saúde.

Torna-se claro que o aumento acelerado na expectativa de vida da população, não é um processo exclusivo das sociedades modernas. No entanto, passou a ser uma preocupação recente tanto nos países desenvolvidos como, de modo crescente, do Terceiro Mundo. Entretanto, é importante ressaltar que este aumento da proporção de idosos, tem se manifestado de forma distinta, considerando as disparidades sociais existentes em cada país. 
(PAIVA, 2014, p. 28). No caso das nações desenvolvidas, este evento ocorreu gradualmente, sendo que primeiro, eles enriqueceram para depois envelhecerem; já nos países em desenvolvimento a situação e bem diferente, eles estão envelhecendo aceleradamente em condições de pobreza (KALACHE, 2007).

No caso do Brasil, o aumento da expetativa de vida da população, se configurou em um fenômeno extremamente rápido, pois o país, vai fazer essa transição em apenas uma geração, no período de 19 anos. Por outro lado, a diversidade observada na idade avançada não é aleatória, se for analisado as características do envelhecimento de nossa população. Primeiramente observa-se que, este fenômeno está se processando em meio as condições de vida, para parcelas imensas da população, ainda muito desfavoráveis. Nesse sentido, pode-se afirmar que a relação com os nossos ambientes físicos e sociais está diretamente relacionado ao impacto desses ambientes, nas oportunidades e comportamentos de saúde, que se nos apresentam ao longo da vida. Grande parte da diversidade que se vivência na idade avançada, é devida ao impacto cumulativo dessas desigualdades de saúde (OPAS, 2018).

A heterogeneidade com que se caracteriza o processo de transição demográfica é influenciada pelas condições de acesso aos direitos civis, sociais e políticos. Sendo então, os condicionantes sócios históricos vivenciados por cada indivíduo, os quais permearão todo seu processo de envelhecimento e velhice, do nascimento até a morte.

Assim, (BOUTIQUE; SANTOS, 2005, p. 85) afirmam que "não existe um envelhecer só, mas processos de envelhecimento de gênero, de etnia, de classe social, de cultura, determinados socialmente". As desigualdades do processo de envelhecimento devem-se, basicamente, às condições desiguais de vida e de trabalho a que as pessoas estiveram submetidas no curso de suas vidas.

Na realidade em questão, fatores associados ao aumento da expectativa de vida da população, trazem consigo enormes desafios para o país, habituado a lidar com questões típicas da população jovem, (a taxa de desemprego, desigualdade econômica e social, insuficiência da aposentadoria, inovação tecnológica acelerada, entre outros problemas). 0 que desencadeia, um processo de exclusão social involuntário, diretamente associada à atividade produtiva nessa faixa etária. Com isso o trabalhador idoso, adquire o estatuto de aposentado, que produz aquele efeito de afastamento, ou seja, sua retirada da sociabilidade 
para o isolamento (SILVA, 2007). Corroborando-se desta forma, como a desigualdade social, aprofunda o abismo brasileiro, reforçando essas iniquidades ainda existentes.

Nessa perspectiva, é valido ressaltar que, ao serem os idosos colocados à margem do processo produtivo formal e do acesso aos já escassos benefícios sociais, são reforçados os fatores determinantes de desenvolvimento de doenças em idosos, aumentando os sintomas depressivos associados às vulnerabilidades socioambientais, psicológicas, familiares e de saúde (MINAYO; CAVALCANTE, 2012); (BARRERO, 2012; PINTO, et al, 2012).

Mesmo assim, ao desvendar a problemática social do envelhecer na sociedade capitalista, vale destacar os caminhos de lutas traçados pelo segmento idoso, ou seja, os marcos legais, a fim de evidenciar as conquistas de direitos, que se inscreveram num processo de mobilização social, até os dias de hoje (COSTA; SOARES, 2016). No Brasil, o direito ao envelhecimento é recente, e o mesmo ocorreu com a normatização dos direitos das pessoas idosas, como dever do Estado, na Constituição Federal (1988) e com a aprovação do Estatuto da pessoa idosa (2003). Tornou de extrema importância, a garantia atenção integral, proteção à vida e à saúde, por meio do movimento de recursos orçamentários e a efetivação de políticas públicas, destinadas às pessoas acima de 60 anos.

Nesse sentido, do ponto de vista da normatização legal, entre os direitos sociais conquistados, destaca-se o direito a educação, no Estatuto do Idoso (2003), no art. 25, em consonância com o art. 10, III, f, da Lei. 842/1994 que atribui ao Poder Público, o dever da promoção do direito à educação do idoso, mediante a instituição da Universidade Aberta à Terceira Idade (UNATI). Tendo em conta que, a educação realiza um papel fundamental no processo de envelhecimento; conhecida por influenciar sentimentos de libertação e mudanças sociais mediante o conhecimento. Neste sentido a educação se torna uma estratégia de empoderamento dos sujeitos.

\section{Descompassos entre o direito e cidadania}

A conquista da Constituição Federal de 1988 (CF/1988) e da Política Nacional do Idoso (PNI) de 1994 e do Estatuto do Idoso de 2003, de atenção à pessoa idosa, ainda não significou a real efetivação da política social (FALEIROS, 2016). O autor aponta um descompasso entre o envelhecimento rápido da população e a lentidão de respostas e implementação de políticas 
públicas, por parte do poder público, demonstrando que a responsabilização acaba por recair sobre a família e o idoso. Reafirma que a adequação das instituições à realidade do envelhecimento está ocorrendo de forma muito lenta.

A longevidade, com dignidade, pressupõe garantir condições do exercício da autonomia, ou seja, a capacidade para poder de pensar e agir de forma participava, no contexto social. Participar implica em ganhar poder, dentro de uma relação de forças. Neste sentido:

Autonomia significa consciência, capacidade e possibilidade relacional para tomar decisões a respeito de si e da sua relação com o mundo, de forma interdependente, num contexto sociopolítico-cultural e como sujeito social e político, com expressão de sua voz e respeito por ela (FALEIROS, 2013b, p. 36).

Na direção da cidadania a CF/1988 estabelece que a família, a sociedade e o Estado devem assegurar ao idoso todos os seus direitos à cidadania com participação na comunidade e defender sua dignidade, bem-estar e direito à vida, conforme o art. 230. O artigo refere que o envelhecimento diz respeito a todos que vivem em sociedade; a discriminação de qualquer natureza contra o idoso deve ser combatida; a pessoa idosa deve se tornar protagonista na proposição e na destinação de políticas específicas; e as diferenças sociais, econômicas e regionais devem ser consideradas na aplicação da política (BRASIL, 1994).

Assim, a cidadania pressupõe dois princípios importantes: a equidade e a efetivação de direitos. A equidade é a busca de oportunidades para todos, na proporção das necessidades de cada um, para superação das desigualdades. A construção dos direitos não leva em conta apenas a especificidade da condição, mas a criação de oportunidades para o envelhecimento com qualidade (OMS, 2005).

Neste artigo se enfatiza que o envelhecimento com qualidade, que pode representar também, a possibilidade de ensinar e aprender. Diante de um mundo marcado por mudanças tecnológica, sociais, econômicas e políticas sem precedentes, torna-se imprescindível a educação, considerando a incompletude do ser humano, conclui-se que está sempre pronto a aprender.

A educação para os idosos representa uma das maiores deficiências na implementação da cidadania, na efetivação de direitos e da participação. É por meio da escolaridade que se tem acesso a informações para melhoria da saúde e da qualidade de vida, redução da violência, entre outros (FALEIROS, 2016). 
Em uma análise sócio histórica, o direito à educação foi negado a grande parte da população idosa em sua trajetória de vida, o que reduz sua autonomia e sua cidadania. Sem educação o enfrentamento da vida cotidiana, torna-se mais difícil, em relação ao as condições de subsistência, ao mundo do trabalho e renda, a participação entre outros. A aprendizagem por outro lado pode ocorrer de maneira informal, pelas trocas espontâneas de experiências, entre pessoas nas famílias, na escola, no trabalho, na comunidade e em outros espaços (ALCÂNTARA, 2016).

A troca de saberes e fazeres entre as gerações promove a aproximação entre as pessoas, a sua humanização e o seu desenvolvimento ético e cultural. Por isso, o direito de ensinar e de aprender dos idosos, deve ser legalmente garantido, por meio da Política Nacional do Idoso (PNI) a Lei no 8.842, de 4 de janeiro de 1994.

O PNI estabelece o direito à educação e ações governamentais da pessoa idosa no inciso III, art. 10, do Capítulo IV, recomendando uma adequação de conteúdo e método no ensino ao idoso; à inserção de informações sobre o envelhecimento na escolarização formal dos jovens; à inclusão da gerontologia nos cursos universitários; à efetivação de programas, principalmente na mídia, que informem a população sobre a questão da velhice; e às ações que incrementem o ensino à distância para os idosos.

O art. 10: "a Política Nacional do Idoso tem por objetivo assegurar os direitos sociais do idoso, criando condições para promover sua autonomia, integração e participação efetiva na sociedade" (BRASIL, 1994). A PNI à intergeracionalidade enfatiza a importância da integração do idoso às demais gerações. Em seu Capítulo II, Seção II, art. 4o, inciso I, a PNI inclui entre suas diretrizes a "viabilização de formas alternativas de participação, ocupação e convívio do idoso, que proporcionem sua integração às demais gerações" (BRASIL, 1994).

A integração social dos idosos pode ser materializada também, por meio dos grupos de convivência. $\mathrm{O}$ contato com pessoas que vivem experiências semelhantes, pode permitir a melhoria auto estima, o autoconhecimento e o estabelecimentos de importantes laços afetivos. Uma das iniciativas de educação que respondem também as necessidades de educação e convívio da pessoa idosa, foram as universidades da terceira idade

A participação das pessoas idosas em equipamentos sociais, grupos e universidades para a terceira idade, ainda que de maneira heterogênea entre a população das diferentes regiões brasileiras, vem aumentando. Nesse sentido, a universidade voltada para o segmento idoso precisa ser considerada um cenário privilegiado para estimular a participação social, 
ampliar as discussões sobre a Política Nacional do Idoso: velhas e novas questões demandas de políticas públicas, e resgatar a dignidade e a cidadania da pessoa idosa. Contudo, a proliferação de tais universidades no país, em universidades públicas e privadas, não tem garantido um acesso igualitário e universal por parte das pessoas idosas. E, embora tenham contribuído para ampliar o protagonismo desta faixa etária, mesmo que de modo tímido e limitado se consideradas as dimensões continentais do país, demandam ainda muito investimento e reflexões. (ASSIS, DIAS, NECHA, 2016, p, 202)

Segundo as autoras as universidades podem representar a conexão entre o direito e a cidadania da pessoa idosa. Porém, apontam que as garantias legais, ainda não foram suficientes para garantir os direitos de forma equitativa nas diferentes regiões do pais. $A$ sociedade clama por uma maior mobilização de líderes locais e agentes políticos, para o envelhecimento da digno e a conquista de uma sociedade mais inclusiva e justa.

\section{Importância da educação na terceira idade}

Entre as inúmeras mudanças ocorridas nos últimos anos relacionados ao envelhecimento humano, a educação lidera, entre as principais preocupações por parte de instituições de ensino aprendizagem, e o quanto é importante satisfazer as pessoas idosas, em sua busca por novos conhecimentos e atividades, assim como necessidades culturais (CORDEIRO, 2007). Em função do crescimento em paralelo da Revolução da Longevidade e a Revolução Tecnológica, se faz necessário uma correspondente Revolução da Educação que traga em si, uma cultura inclusiva do direito ao aprendizado ao longo da vida (KALACHE, 2019). Em base disso, ressalta-se a importância de superar a ideia de assistencialismo ou de infantilização da velhice, pela valorização do idoso (OLIVEIRA, 2012).

Reconhecido pela Declaração Universal dos Direitos Humanos de 1948, a Educação é um direito à instrução do qual todas as pessoas têm direito e a mesma deve ser orientada ao pleno desenvolvimento da personalidade humana e também ao fortalecimento e ao respeito pelos direitos humanos e às liberdades fundamentais (COSTA; COSTA; GOBBI, 2012). Por outro lado, as Nações Unidas (UN) destacam a educação como uma das questões prioritárias, dentro da agenda de desenvolvimento global. Motivo pelo qual, a adoção de políticas públicas no âmbito da educação, devem direcionar suas estratégias, além das ações de assistência e 
prevenção à saúde, enfatizando a importância de discutir temas relacionados ao envelhecimento humano, dentro das escolas e universidades (UN, 2013).

Freire (2006) salienta que a educação precisa estar alinhada com a realidade de cada indivíduo, sendo necessário então, que o próprio indivíduo seja capaz de reinventar e transformar sua própria educação, em função das suas necessidades. Tendo em conta que, a educação é uma variável importante sobre as desigualdades em saúde e no status socioeconômico das pessoas, considera-se que o investimento em educação, também é um investimento em saúde e bem-estar (WHO, 2015).

Para Ordonez e Cachioni (2011), os programas educacionais oferecidos dentro das universidades para este grupo etário, são meios que promovem saúde, bem-estar psicológico e social, tanto em curto ou longo prazo. Nessa perspectiva no Brasil, no âmbito da promoção de um viver saudável, enquanto transcorre o processo do envelhecimento, as universidades têm oferecido programas voltados para a educação permanente desses adultos maduros e idosos.

Assim, as primeiras iniciativas educacionais brasileiras direcionadas ao atendimento de adultos e idosos foram adaptadas pelo Serviço Social do Comércio (SESC), que está sintonizado com os movimentos educacionais da Europa, sobretudo da França, que inaugurou um novo modelo de atendimento ao idoso: as Escolas Abertas para a Terceira Idade. Nessa perspectiva, o espaço universitário se reveste de fundamental importância, como líder ao introduzir desde inicios dos 1970, programas que visam a atualização de informações e o desenvolvimento de novas habilidades, de lazer e convivência para os idosos (SESC, 2010).

O sucesso dessa experiência inspirou a criação das Universidades Abertas à Terceira Idade, hoje espalhadas por todo o Brasil, as quais têm por finalidade oferecer apoio social que possibilita o empoderamento e autonomia, assim como a reinserção dos idosos na sociedade, além de propiciar espaços para rico contato intergeracional, e oportunidades para a discussão de crenças e atitudes acerca da velhice e de evidenciação, de que é possível aprender e se desenvolver durante essa fase da vida (DÁTILO; TAVARES, 2012; CACHIONI, 2005).

\section{Universidade aberta como estratégia de promoção de saúde}


Considerando a educação como um caminho promissor para atingir esses fins, estudos brasileiros realizados sobre a experiência de idosos, nas chamadas Universidades para à Terceira Idade, têm considerado um impacto positivo, no uso de algumas práticas desenvolvidas nesses espaços. Nessa perspectiva as Universidades Abertas à Terceira Idade (UNATI) se reveste de fundamental importância como uns dos espaços propícios, dentro da sociedade, para refletir o papel que o idoso ocupa na mesma. Desta forma a relevância social da proposta da UNATI, se ratifica na inclusão social do idoso, por meio do convívio com outras gerações, transformando a realidade social e política do mesmo (VERAS; CALDAS, 2004). Além disso, pretende propiciar condições para um novo olhar acerca do envelhecimento humano, a fim de que, os idosos, comecem a ser considerados protagonistas de direitos e deveres (OLIVEIRA; SCORTEGAGNA, 2015).

A área de Saúde e de educação são constantemente interligadas, quando a questão, gira em torno das condições de vida. A interação entre elas, independentemente de onde ocorre a mesma - escola ou serviço de saúde - tem ganhado espaço no discurso no campo da saúde, revigorando-se cada vez mais, já que constitui um caminho importante para a conquista da qualidade de vida, sendo no conceito de promoção da saúde (PS), sua estratégia central. As primeiras abordagens foram conhecidas a partir Relatório Lalonde 1974, no Canadá, quando se definiu as bases de um movimento pela Promoção de Saúde, trazendo como consigna básica adicionar não só anos à vida, mas vida aos anos (PAIM; ALMEIDA FILHO, 2000).

Tomando como base na concepção atual, no ano de 1980 a OMS, define à PS como o "processo de capacitação da comunidade para atuar na melhoria de sua qualidade de vida e saúde, incluindo uma maior participação no controle desse processo" (BRASIL, 2002a), definição posteriormente consagrada na Carta de Otawa, sendo reconhecida como o marco teórico desse movimento, resultante da 1ạ Conferência Internacional de Promoção da Saúde, em 1986. Atualmente a PS pode ser compreendida como um conjunto de estratégias e formas de produzir saúde, no âmbito individual e coletivo, caracterizada pela articulação de ações de cooperação intra e intersetorial com as demais redes de proteção social, com ampla participação social e controle (BRASIL, 2014).

Em função disso, a educação em saúde é um dos principais eixos estratégicos para a PS e na promoção do envelhecimento ativo (MALDONADO; MUÑOZ; NÚÑEZ, 2007), a qual 
contribui para a diminuição das vulnerabilidades nesse grupo, por meio da troca de saberes. Nesse âmbito, cabe à educação em saúde, promover hábitos de vida saudáveis ao articular saberes técnicos e populares (FERNANDES; SIQUEIRA, 2010). Já que, com frequência, na velhice, a manutenção de autonomia, está intimamente ligada à qualidade de vida, a qual reflete diretamente numa maior autoconfiança, participação social e econômica, e estilos de vida mais saudáveis.

Domingues e Derntl (2008, p. 169) defendem a necessidade de construção de relações e redes sociais de apoio comunitário para os idosos, entre as quais podem ser identificados os "programas que estimulem a autonomia dos idosos". É valido mencionar a Universidade Aberta à Terceira Idade (UNATI) como uma das instituições, entre as quais essas atividades, podem ser realizadas de várias formas.

De acordo com Jodelet (2001), as representações sociais são formas de conhecimento, elaboradas e compartilhadas socialmente, que possuem como objetivo prático a interpretação dos diferentes aspectos da realidade. Nesse sentido Dátilo e Tavares (2012) apontam que a predominância de idosos, frequentando as UNATI, pode ser atribuída a busca de obter maiores conhecimentos e se manterem atualizados, estimulando a troca de saberes, seguido da necessidade em fazer novos amigos, exercitar a memória visando uma velhice com qualidade de vida, dedicar um tempo a si próprio, ter lazer e uma ocupação saudável.

Em uma revisão sistemática sobre intervenções de empoderamento para pessoas idosas, Shearer, et al. (2012), verificaram que as intervenções realizadas com um grupo de idosos, que sofriam com problemas de saúde mental, mediante a educação, estimularam o empoderamento desse grupo, influenciando na redução da depressão e ansiedade, assim como aumentou o conhecimento e a capacidade, para a tomada de decisões em relação aos problemas de saúde, como diabetes, hipertensão e auto eficácia dos participantes.

Outro estudo realizado pelas autoras Cachioni e Ordonez (2011), com um grupo constituído por mulheres idosas de 64,57 anos de idade, tinha por objetivo caracterizar os principais motivos, pelos quais, frequentavam o programa da UNATI. Como principais resultados obtidos, encontrou-se uma procura elevada desse programa, a fim de investir no próprio desenvolvimento por parte dos participantes, além disso, mais da metade dos entrevistados, disseram que aumentar os conhecimentos, foi o primeiro motivo que os trouxe ao programa, seguido do aperfeiçoamento pessoal. 
Tendo em conta que, nesta etapa de transição populacional, na qual o idoso assume diferentes papéis e condições econômicas, sociais e familiares, além de mudanças marcantes no seu estereotipo, é importante que o idoso, seja visto como uma pessoa de direito, ativo e autônomo. Nessa ótica, Lopes (2012), refere-se à necessidade de promover ações em que o idoso, aprenda a lidar com as transformações que ocorrem em seu corpo, sabendo dos seus direitos, conquistando sua autonomia, para sentir-se sujeito de sua própria história.

\section{Conclusões}

Entende-se que na vigência das políticas e serviços apropriados, o envelhecimento da população, pode ser considerado uma preciosa oportunidade, tanto para os indivíduos, como para sociedade. Não entanto, é sabido que, para lograr reverter a atual situação que as pessoas idosas vêm enfrentando, com relação aos riscos e danos provenientes das discriminações desta faixa etária, exigem-se mudanças essenciais ancoradas aos métodos inovadores e imaginativos, repensando ou ressignificando o processo de envelhecimento em si.

Neste sentido, as universidades por meio do ensino, pesquisa e extensão nos dias de hoje, possuem um papel importante no processo de envelhecimento da sociedade, onde espaços como a UNATI, podem contribuir com a inserção da pessoa idosa, no contexto acadêmico, com possibilidades de aprendizagem, convívio Inter geracional, de forma mais autônoma, livre e criativa, fundamental para o seu bem-estar físico e psicológico. Desta maneira, sugere-se a intensificação outras atividades, na área do envelhecimento, que direcionem esforços para ampliar a importância, o papel e os benefícios destes espaços, como as UNATI dentro das universidades, como lócus de ações educativas em promoção da saúde, no sentido de contribuir para uma velhice digna, saudável, visando melhorar a qualidade de vida desta população.

\section{Referencias}

ASSIS, M. G.; DIAS, R. C.; NECHA, R. M. A universidade para a terceira idade na construção da cidadania da pessoa idosa. In: ALCÂNTARA, Alexandre de Oliveira; CAMARANO, Ana Amélia, GIACOMIN, Karla Cristina. Política nacional do idoso: velhas e novas questões. Rio de Janeiro: Ipea, 2016. 615 p. 
ALCÂNTARA, A. de O. Da política nacional do idoso ao estatuto do idoso: a difícil construção de um sistema de garantias de direitos da pessoa idosa. In: ALCÂNTARA, Alexandre de Oliveira; CAMARANO, Ana Amélia, GIACOMIN, Karla Cristina. Política nacional do idoso: velhas e novas questões. Rio de Janeiro: Ipea, 2016. 615 p.

BARRERO, S. A. P. Fatores de risco suicida no mundo. Ciênc. Saúde coletiva, Rio de Janeiro, v. 17, n. 8, p. 2011-2016, agosto de 2012. Disponível em:

http://www.scielo.br/scielo.php?script=sci_arttext\&pid=S1413-

$81232012000800012 \&$ Ing=en\&nrm=iso. Acesso em: $18 \mathrm{de} \mathrm{fev.} 2020$.

https://doi.org/10.1590/S1413-81232012000800012

BRASIL. Estatuto do Idoso - Lei n. 1.741/2003. Brasília: Senado Federal, 2005.

BRASIL. As Cartas da Promoção da Saúde. Brasília: Ministério da Saúde, 2002a.

BRASIL. Ministério da Saúde. Portaria n².446, de 11 de novembro de 2014. Redefine a Política Nacional de Promoção da Saúde (PNPS). Disponível em: http://bvsms.saude.gov. br/bvs/saudelegis/gm/2014/prt2446_11_11_2014.html. Acesso em: 15 mar. 2018.

BOUTIQUE, N. C.; SANTOS, R. de L. A. dos. Aspectos Socioeconômicos do Envelhecimento. In: NETTO, Matheus Papaléo. Gerontologia. São Paulo: Atheneu, 2005. P. 82-91.

CACHIONI, M. Universidade da Terceira Idade. In: NERI, A.L. (Org.). Palavras chave em Gerontologia. Campinas: Alínea. p. 207-210. 2005.

CAMPELO E PAIVA, S. O. Envelhecimento, saúde e trabalho no tempo do capital. São Paulo: Cortez, 2. ed. 2014.

CAVALCANTE, F. G.; MINAYO, M. C. S. Autópsias psicológicas e psicossociais de idosos que morreram por suicídio no Brasil. Ciênc. Saúde coletiva, Rio de Janeiro, v. 17, n. 8, p. 19431954, ago. 2012. Disponível em:

http://www.scielo.br/scielo.php?script=sci_arttext\&pid=S1413-

$81232012000800002 \&$ Ing=pt\&nrm=iso. Acesso

em: 18 fev. 2020. https://doi.org/10.1590/S1413-81232012000800002.

CORDEIRO, A. P. Envelhecimento e arte: as oficinas de teatro da UNATI- UNESP de Marília em cena. In: BRUNS, M. A. D. T.; DEL-MASSO, M. C. S. (Org.). Envelhecimento humano: diferentes perspectivas. Campinas: Alínea, p. 91-119. 2007.

COSTA, D. G. S.; SOARES, N. Envelhecimento e velhices: heterogeneidade no tempo do capital. Serviço Social \& Realidade, Franca, v. 2, n. 25, p.57-68, dez. 2016.

COSTA, J. L. R.; COSTA, A. M. M. R.; GOBBI, S. Unesp - Unati e as políticas públicas voltadas à população idosa. In: DEL-MASSO, M.C.S.; AZEVEDO, T.C.A. (Org.). UNATI Universidade Aberta da Terceira Idade, UNESP - PROEX. São Paulo: Cultura Acadêmica, 2012. p. 25-41. 
DÁTILO, G. M. P. A.; TAVARES, F. C. Percepção da importância da participação de idosos em uma Universidade Aberta da Terceira Idade. Revista Equilíbrio Corporal e Saúde, São Paulo, v. 4 , n. 1, p. 28-41, 2012.

DOMINGUES, M. A.; DERNTL, A. M. Relações e redes sociais. In: JACOB FILHO, W.; GORZONI, M. L. Geriatria e gerontologia: o que todos devem saber. São Paulo: Roca, p. 165-180, 2008.

FALEIROS, V. de P. A política nacional do idoso em questão: passos e impasses na efetivação da cidadania. In: ALCÂNTARA, Alexandre de Oliveira; CAMARANO, Ana Amélia, GIACOMIN, Karla Cristina. Política nacional do idoso: velhas e novas questões. Rio de Janeiro: Ipea, 2016. $615 \mathrm{p}$.

FALEIROS, V. de P. Autonomia relacional e cidadania protegida: paradigmas para envelhecer bem. In: CARVALHO, M. I. de (Org.). Serviço social no envelhecimento. Lisboa: Pactor, 2013b. p. $35-48$.

FERNANDES, M. T. O.; SOARES, S. M. O desenvolvimento de políticas públicas de atenção ao idoso no Brasil. Rev. esc. enferm. USP, São Paulo, v. 46, n. 6, p. 1494-

1502, Dec. 2012. Disponível em:

http://www.scielo.br/scielo.php?script=sci_arttext\&pid=S0080

62342012000600029\&Ing=en\&nrm=iso. Acesso em: 17 nov.

2019. https://doi.org/10.1590/S0080-62342012000600029.

FERNANDES, W. R.; SIQUEIRA, V. H. F. Educação em saúde da pessoa idosa em discursos e práticas: atividade física como sinônimo de saúde. Interface: Botucatu, v. 14, n. 33, p. 371385, June 2010. Disponível em:

http://www.scielo.br/scielo.php?script=sci_arttext\&pid=S1414

$32832010000200011 \& \operatorname{lng}=e n \& n r m=i s o$. Acesso

em: 20 fev. 2020. https://doi.org/10.1590/S1414-32832010000200011.

FREIRE, P. Pedagogia da esperança. 13a ed. Rio de Janeiro: Paz e Terra, 2006.

JODELET, D. Representações sociais: um domínio em expansão. In: JODELET, D. (Org.). As representações sociais. Rio de Janeiro: EdUERJ, p. 17-44, 2001.

KALACHE, A. Prefácio. In: FRANÇA, L.; STEPANSKY, D. (Orgs.). Propostas multidisciplinares para o bem-estar na aposentadoria. Rio de Janeiro: Quartet; Faperj, 2012.

KALACHE, A. Fórum. Informações sobre envelhecimento da população e saúde da Pesquisa Nacional por Amostra de Domicílios: demandas e desafios contemporâneos. Postscript. Cafajeste. Saúde Pública, Rio de Janeiro, v. 23, n. 10, p. 25032505, outubro de 2007. Disponível em:

http://www.scielo.br/scielo.php?script=sci_arttext\&pid=S0102-

$311 X 2007001000024 \&$ Ing=en\&nrm=iso. Acesso em 18 de fev.

2020. https://doi.org/10.1590/S0102-311X2007001000024

KALACHE, A. Uma revolução da educação em resposta à revolução da longevidade. Rev. bras. geriatr. gerontol., Rio de Janeiro, v. 22, n. 4, e 190213, 2019. Disponível em: http://www.scielo.br/scielo.php?script=sci_arttext\&pid=S1809 
$98232019000400206 \& \operatorname{lng}=e n \& n r m=$ iso. Acesso em: 25 jan. 2020. http://dx.doi.org/10.1590/1981 22562019022.190213

LE PHAM, P. D.; VO, T. Q. Assessment of psychometric properties of WHOQOL-OLD instrument: a literature review. International Journal of Pharmacy and Pharmaceutical Research, Baltimore, v. 4, n. 4, p. 53-66, 2015.

LOPES, M. E. P. S. A velhice no século XXI: a vida feliz e ainda ativa na melhor idade. Acta Scientiarum Human and Social Sciences, v. 34, n. 1, 2012. Disponível em: http://www.periodicos.uem.br/ojs/index.php/ActaSciHumanSocSci/article/view/1 197. Acesso em: 10 jul, 2019.

MALDONADO, M. L. M; MUÑOZ, E. C; NÚÑEZ, V. M. M. Program of active aging in a rural Mexican community: a qualitative approach. BMC Public Health 7:276; 2007.

MALTA, D. C.; MORAIS NETO, O. L.; SILVA JUNIOR, J. B. Apresentação do plano de ações estratégicas para o enfrentamento das doenças crônicas não transmissíveis no Brasil, 2011 a 2022. Epidemiol. Serv. Saúde, Brasília, v. 20, n. 4, p. 425-438, dez. 2011. Disponível em http://scielo.iec.gov.br/scielo.php?script=sci_arttext\&pid=S1679-

49742011000400002\&lng=pt\&nrm=iso. Acesso em:

18 jan. 2020. http://dx.doi.org/10.5123/S1679-49742011000400002.

MONTEAGUDO, R. A. M.; GARCÍA, Y. M. Envejecimiento demográfico en Cuba y los desafíos que presenta para el Estado. Medwave. 18. e7231-e7231. 10.5867/medwave.2018.04.7231. 2018.

OLIVEIRA, R. C. S. Reconstruçâo histórica da universidade aberta para a terceira idade na Universidade Estadual de Ponta Grossa. Revista HISTEDBR On-line, v. 12, n. 45e, p. 142-161, 11. mai, 2012.

OLIVEIRA, R. C. S.; SCORTEGAGNA, P.A. Apresentação, set., 2014. In: OLIVEIRA, Rita de Cássia da Silva; SCORTEGAGNA, Paola Andressa (Org.). Universidade Aberta para a Terceira Idade: o idoso como protagonista na extensão universitária. Ponta Grossa: Editora UEPG, p. 13-18. 2015.

ORDONEZ, T. N.; CACHIONI, M. Motivos para frequentar um programa de educação permanente: relato dos alunos da universidade aberta à terceira idade da Escola de Artes, Ciências e Humanidades da Universidade de São Paulo. Rev. bras. geriatr. gerontol. Rio de Janeiro, v. 14, n. 3, p. 461-474, 2011. Disponível em:

http://www.scielo.br/scielo.php?script=sci_arttext\&pid=S1809

98232011000300007\&lng=en\&nrm=iso. Acesso em:

20 fev. 2020. https://doi.org/10.1590/S1809-98232011000300007.

ORGANIZAÇÃO PAN-AMERICANA DA SAÚDE (OPAS). Folha informativa - Envelhecimento e saúde. 2018. Disponível em:

https://www.paho.org/bra/index.php?option=com_content\&view=article\&id=5661:folhainf ormativa-envelhecimento-e-saude\&Itemid=820. Acesso em: 14 mai. 2019. 
PAIM J. S.; ALMEIDA Filho, N. A crise na saúde pública e utopia da saúde coletiva. Salvador: Casa da Qualidade, Editora; 2000.

PAIVA, S. O. C. Envelhecimento, saúde e trabalho no tempo do capital. 1. ed. São Paulo: Cortez, 2014.

PINTO, L. W. et al. Evolução temporal da mortalidade por suicídio em pessoas com 60 anos ou mais nos estados brasileiros, 1980 a 2009. Ciênc. saúde coletiva, Rio de Janeiro, v. 17, n. 8, p. 1973-1981, ago. 2012. Disponível em: http://www.scielo.br/scielo.php?script=sci_arttext\&pid=S1413$81232012000800008 \& \operatorname{lng}=p t \& n r m=i s o$. Acesso em: 18 fev. 2020. https://doi.org/10.1590/S1413-81232012000800008.

PRATA, H. L.; ALVES, E. D. J.; PAULA, F. L.; FERREIRA, S. M. Fisioterapia. Mov., Curitiba, v. 24, n. 3, p. 438, jul./set. 2011.

SERVICO SOCIAL DO COMERCIO (SESC). O Perfil das Universidades da Terceira Idade no Estado de São Paulo. A Terceira Idade: Estudos sobre Envelhecimento /Serviço Social do Comércio. v. 21 - no 47, mar, de 2010. ISSN 1676-0336.

SILVA, Sobrinho, H. F. Discurso, velhice e classe sociais: a dinâmica contraditória do dizer agitando as filiações de sentido na processualidade histórica. Maceió: EDUFAL, 2007.

SHEARER, N., Fleury, J., WARD, K.; O'BRIEN, A. M. (2012). Empowerment interventions for older adults. Western Journal of Nursing Research, 34, 24-51. doi:

10.1177/0193945910377887

UNITED NATIONS (UN). Secretary-General. Report of the high level panel of eminent persons on the Post-2015 Development Agenda (UN, 2013). Report of the Global Thematic Consultation on Education in the Post-2015: Development Agenda. New York: UNESCOUNICEF; 2013.

VENTURA, M. F. O uso de plantas medicinais por grupo de idosos de unidade de saúde de Campo Grande, Rio de Janeiro: uma discussão para a implantação da fitoterapia local. 2012. 52 f. TCC (Graduação) - Curso de Gestão da Inovação de Fitomedicamentos, Instituto de Tecnologia em Fármacos, Fundação Oswaldo Cruz. Instituto de Tecnologia em Fármacos/farmanguinhos, Rio de Janeiro, 2012. Disponível em: http://www.arca.fiocruz.br/bitstream/icict/7716/2/33.pdf. Acesso em: 31 ago. 2018.

VERAS, R. P.; CALDAS, C.P.; CORDEIRO, H.A. Modelos de atenção à saúde do idoso: repensando o sentido da prevenção. Physis. Rio de Janeiro , v. 23, n. 4, p. 11891213, Dec. 2013.

VERAS, R. P. Gerenciamento de doença crônica: equívoco para o grupo etário dos idosos. Revista de Saúde Pública, São Paulo, v. 46, n. 6, p. 929-934, dez. 2012a.

VERAS, R. P.; CALDAS, C.P. Promovendo a saúde e a cidadania do idoso: o movimento das universidades da terceira idade. Ciência \& Saúde Coletiva, Rio de Janeiro, v. 9, n. 2, p. 423- 
432, 2004. Disponível em: http://www.scielosp.org/pdf/csc/v9n2/20396.pdf. Acesso em: out. 2019.

WORLD HEALTH ORGANIZATION (WHO) Envelhecimento ativo: uma política de saúde. Brasília: Organização Pan-Americana da Saúde, 2005. Disponível em:

http://www.scielo.br/scielo.php?script=sci_nlinks\&ref=000137\&pid=S0103166X200800040001300026\&lng=en. Acesso em: 20 jan. 2020.

WORLD HEALTH ORGANIZATION (WHO). World report on ageing and health. Geneva: WHO; 2015. Disponível em: http://apps.who.int/ iris/bitstream/10665/186463/1/9789240694811_eng. pdf?ua. Acesso em: 15 jun. 2018.

WIXEY, S. et al. Measuring Accessibility as Experienced by Different Socially Disadvantaged Groups, funded by the EPSRC FIT Programme - Transport Studies Group - Universidade de Westminster, p.18, 2005. 